\title{
Rancang Bangun Media Pembelajaran Avionic - Radio Theory II Berbasis Multimedia Animasi pada ATKP Medan
}

\author{
Dwiyanto $^{1}$, Catra Indra $\mathbf{C}^{1}$, Ahmad Faisal ${ }^{1}$, Iswandi Idris ${ }^{2, *}$, Rizaldy Khair ${ }^{2}$ \\ ${ }^{1}$ Teknik Listrik Bandar Udara, Politeknik Penerbangan Medan, Medan, Indonesia \\ ${ }^{2}$ Teknologi Komputer, Politeknik LP3I Medan, Medan, Indonesia \\ Email:1'dwiyanto13@atkpmedan.ac.id, ${ }^{2}$ catraindracahyadi@gmail.com, ${ }^{4, *}$ iswandi.idris@plm.ac.id, \\ 5rizaldyk.lp3i@gmail.com \\ Email Penulis Korespondensi: iswandi.idris@plm.ac.id
}

\begin{abstract}
Abstrak-Pentingnya Media Pembelajaran dimanfaatkan oleh ATKP Medan untuk terus meningkatkan mutu pembelajaran, Permasalahan yang sering dijumpai dalam pembelajaran avionic adalah keterbatasan resource yang ada karena untuk mengakses pembelajaran avionic para taruna harus mengakses dari LAB CBT dan tidak bisa dari tempat lain. Hal ini disebabkan software Avionic hanya terpasang didalam lab dan tidak bisa dipelajari dari luar lab. Tujuan dalam penelitian ini adalah meningkatkan proses pembelajaran avionic- Radio Theory II secara digital yang dkemas dalam animasi multimedia untuk Memudahkan para taruna untuk mempelajari avionic Radio Theory II tanpa harus akses di laboratorium. Metode yang digunakan dalam penelitian ini adalah menggunakan Dengan menggunakan metode Multimedia Development Life Cycle MDLC yaitu metode Konsep (Concept), perancangan (desain), pengumpulan bahan (material collecting), pembuatan (assembly), pengujian (testing), distribusi (distribution)
\end{abstract}

Kata Kunci: Media Pembelajaran, Avionic, Radio Theory II, ATKP Medan.

Abstract-The importance of Learning Media is used by ATKP Medan to continuously improve the quality of learning. The problem that is often encountered in avionic learning is the limited resources available because to access avionic learning the cadets must access from the CBT LAB and cannot be from elsewhere. This is because Avionic software is only installed inside the lab and cannot be learned from outside the lab. The purpose of this research is to improve the digital avionic-Radio Theory II learning process which is packaged in multimedia animation to make it easier for cadets to learn avionic Radio Theory II without having to access it in the laboratory. The method used in this research is to use the MDLC Multimedia Development Life Cycle method, namely the Concept concept, design, material collection, assembly, testing, distribution, distribution, The resulting output is an animated video product and publication to the ISSN journal.

Keywords: Learning Media, Avionic, Radio Theory II, ATKP Medan

\section{PENDAHULUAN}

Media audio motion visual (media audio visual gerak) yakni media yang mempunyai suara, ada gerakan dan bentuk obyeknya dapat dilihat, media ini paling lengkap. Informasi yang disajikan melalui media ini berbentuk dokumen yang hidup, dapat dilihat dilayar monitor atau ketika diproyeksikan ke layar lebar melalui projector dapat didengar suaranya dan dapat dilihat gerakannya (video atau animasi).

Media pembelajaran dapat dipahami segala sesuatu yang dapat menyampaikan dan menyalurkan pesan dari sumber secara terencana sehingga tercipta lingkungan belajar yang kondusif dimana penerimanya dapat melakukan proses belajar secara efesien dan efektif [1]. Media pembelajaran merupakan suatu hal yang sangat penting dan melengkapi keberhasilan proses pendidikan [2]. Pemanfaatan media pembelajaran merupakan upaya kreatif dan sistematis untuk menciptakan pengalaman yang dapat membelajarkan siswa sehingga pada akhirnya lembaga pendidikan akan mampu menghasilkan lulusan yang berkualitas [3]. Media pembelajaran merupakan segala sesuatu yang dapat digunakan untuk mengantarkan atau menyampaikan pesan, berupa sejumlah pengetahuan, keterampilan, dan sikap - sikap kepada peserta didik sehingga peserta didik itu dapat menangkap, memahami, dan memiliki pesan - pesan dan makna yang disampaikan[4]. Multimedia interaktif dirancang untuk proses belajar mandiri karena siswa diberikan keleluasaan dalam mengoperasikan media pembelajaran multimedia interaktif [5]. Meningkatkan pengetahuan dan ketrampilan [6], meningkatkan layanan dan kepuasan pelanggan [7]

Pentingnya Media Pembelajaran juga dimanfaatkan oleh ATKP Medan untuk terus meningkatkan mutu pembelajaran, Akademi Teknik dan Keselamatan Penerbangan (ATKP) Medan merupakan institusi pendidikan kedinasan dibawah Kementrian Perhubungan yang bergerak dalam bidang penerbangan memiliki empat program studi unggulan antara lain, pemandu lalu lintas udara, teknik listrik bandara, teknik telekomunikasi dan navigasi udara, serta teknik pesawat udara.

Avionic merupakan peralatan elektronik penerbangan yang mencakup seluruh sistem elektronik yang dirancang untuk digunakan di pesawat terbang. Sistem utamanya meliputi sistem komunikasi, navigasi dan indikator serta manajemen dari keseluruhan sistem. Avionik juga mencakup ratusan sistem yang berada di pesawat terbang dari yang paling sederhana seperti lampu pencari pada helikopter polisi sampai sistem yang kompleks seperti sistem taktikal pada pesawat peringatan dini [8]. Selama ini pembelajaran avionic dilakukan di LAB CBT dengan aplikasi desktop yang sudah terinstal didalamnya yang langsung terkoneksi ke server di New York. Hal ini cukup menyulitkan para taruna dalam proses pembelajaran, cukup menyulitkan dalam mengulang pembelajaran karena satu satunya akses adalah akses kedalam LAB CBT, terutama untuk materi Radio Theory II. Untuk itu dibutuhkan suatu media pembelajaran dalam bentuk rancang bangun berbasis multimedia animasi.

Berdasarkan latar belakang tersebut maka rumusan masalah yang dapat diidentifikasi pada penelitian ini adalah : Bagaimana Rancang Bangun Media Pembelajaran Avionic Radio Theory II Berbasis Multimedia Animasi pada ATKP Medan. 


\section{METODE PENELITIAN}

Penelitian yang peneliti buat menggunakan metode penelitian metode studi pustaka dan observasi yaitu sebagai berikut:

1. Observasi

Peneliti melakukan pengamatan secara langsung mengenai pembelajaran avionik Radio Theory II di LAB.

2. Studi Pustaka

Peneliti mencari literatur bacaan serta sumber referensi yang mendukung dan berkaitan dengan topik yang peneliti ambil agar mendapat landasan teoritis yang akurat.

Pengembangan Digitalisasi Media Pembelajaran Avionic untuk Implementasi dalam penelitian ini menggunakan metode Multimedia Development Life Cycle (MDLC) [9].

\section{HASIL DAN PEMBAHASAN}

Penelitian ini menggunakan metode penelitian metode studi pustaka dan observasi yaitu sebagai berikut:

1. Observasi

Peneliti melakukan pengamatan secara langsung mengenai pembelajaran avionik Radio Theory II di LAB.

2. Studi Pustaka

Peneliti mencari literatur bacaan serta sumber referensi yang mendukung dan berkaitan dengan topik yang peneliti ambil agar mendapat landasan teoritis yang akurat.

Pengembangan Digitalisasi Media Pembelajaran Avionic untuk Implementasi dalam penelitian ini menggunakan metode Multimedia Development Life Cycle (MDLC) [9] yang terdiri dari 6 tahap. Tahapan-tahapan dalam MDLC yang tersusun secara sistematis adalah sebagai berikut:

1. Konsep (Consept)

2. Perancangan (Desain)

3. Pengumpulan Bahan (Material Collecting)

4. Pembuatan (Assembly)

5. Pengujian (Testing)

6. Distribusi (Distribution)

Didalam Rancang Bangun Media Pembelajaran Avionic - Radio Theory II ini terdapat 8 sub video:

a. Introduction

b. Types of Antennas

c. Transmitters

d. Oscilators

e. Detector, AGC, \& Noise LImiters

f. Muting circuits, Modulators, \& RF Power Amplifiers

g. Matching Units \& Filters

Dimana masing masing video akan menjelaskan secara detail point point penting dalam Radio Theory II dalam durasi menit dengan menampilkan MULTIMEDIA ANIMASI berisi text dan suara untuk penjelasan.

\subsection{Perancangan}

Desain di Rancang Bangun Media Pembelajaran Avionic - Radio Theory II ini terdapat beberapa jenis yaitu : a. Halaman Introduction

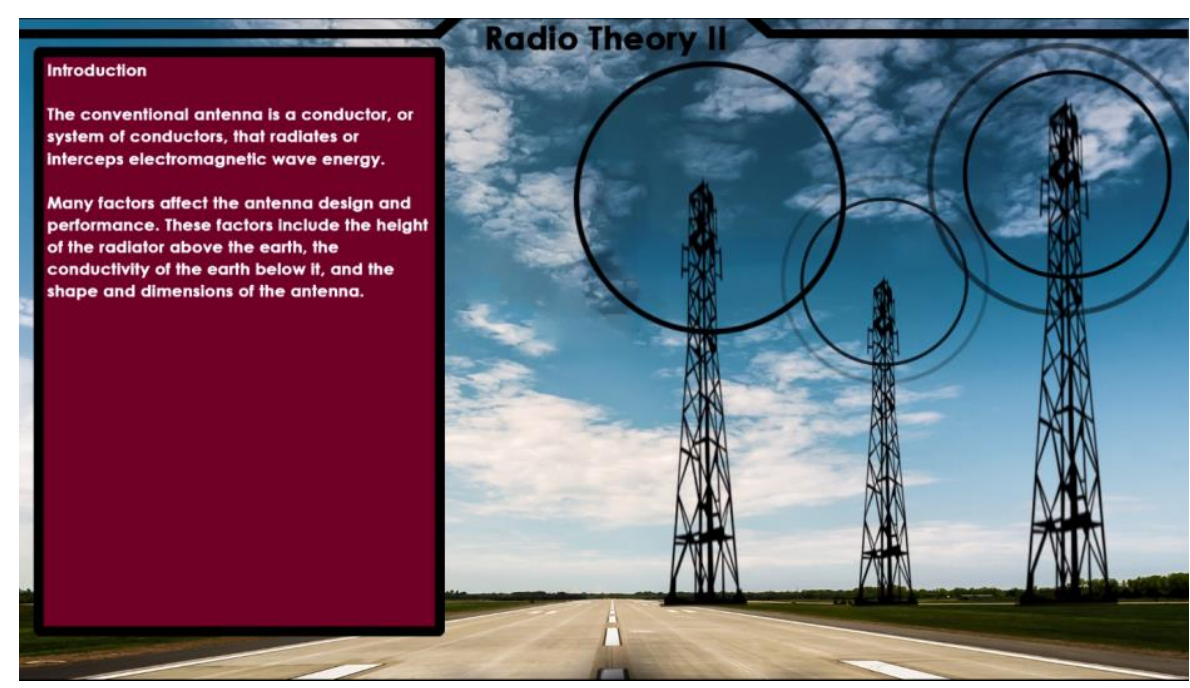

Gambar 1. Halaman Introduction 
JSON Volume 1, Nomor 3, Mei 2020

e-ISSN 2685-998X

DOI 10.30865/json.v1i3.2185

b. Halaman Types of Antennas

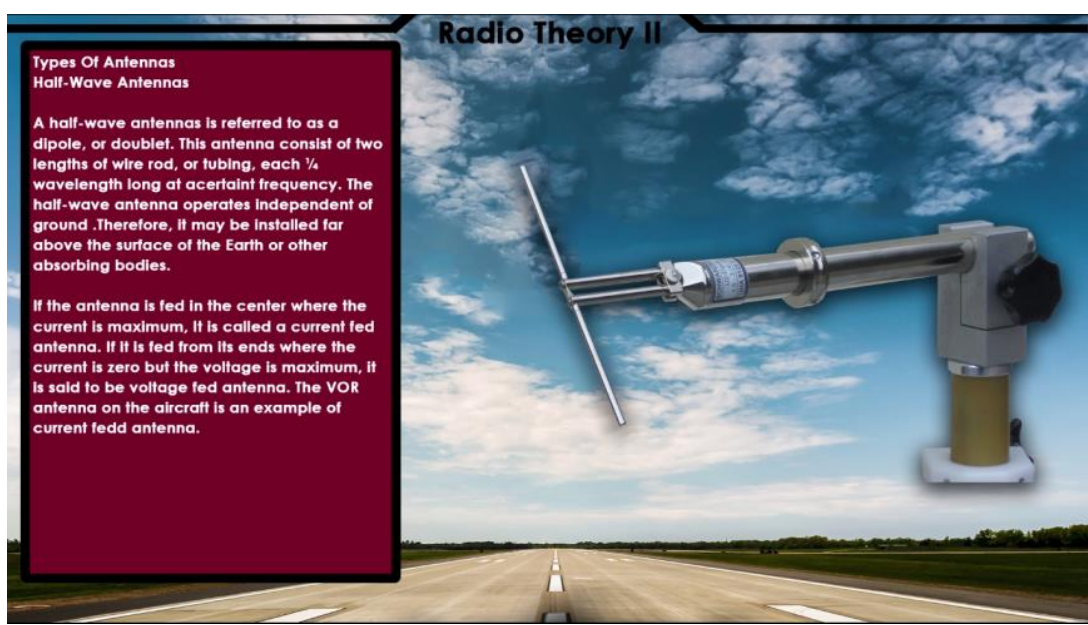

Gambar 2. Halaman Types of Antennas

c. Halaman Transmitters

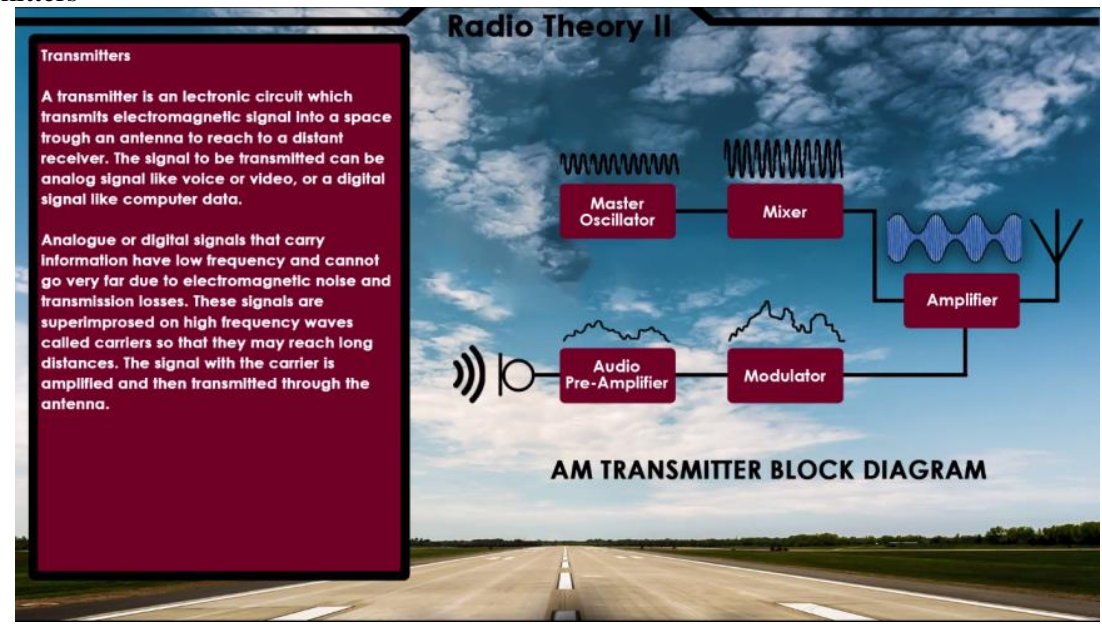

Gambar 3. Halaman Transmitters

d. Halaman Oscilators

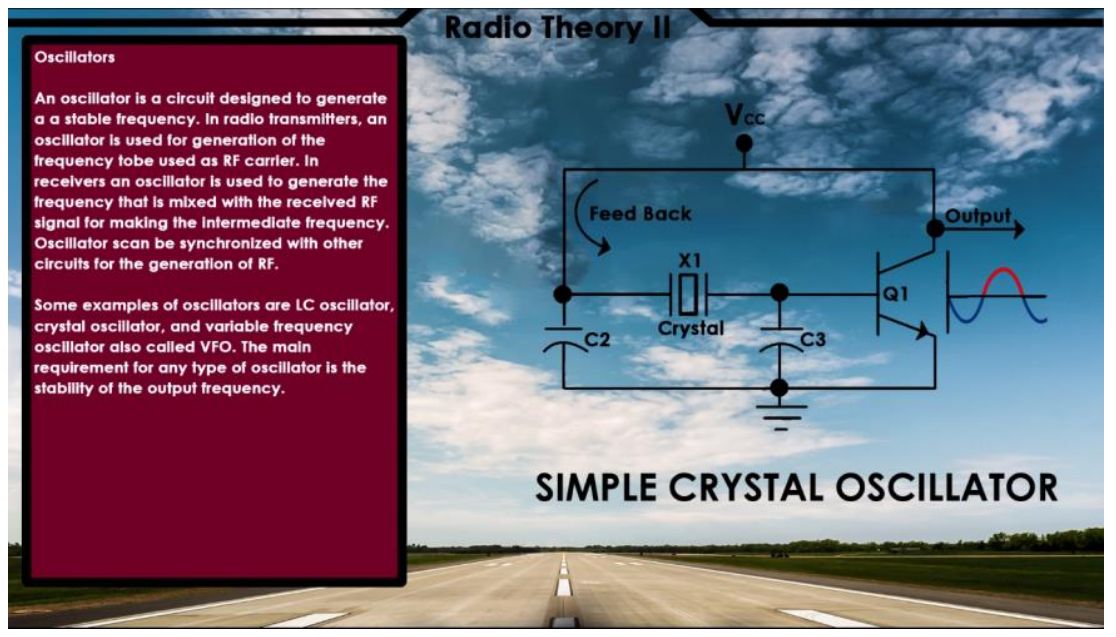

Gambar 4. Halaman Oscilators 
JSON Volume 1, Nomor 3, Mei 2020

e-ISSN 2685-998X

DOI 10.30865/json.v1i3.2185

f. Halaman Detector

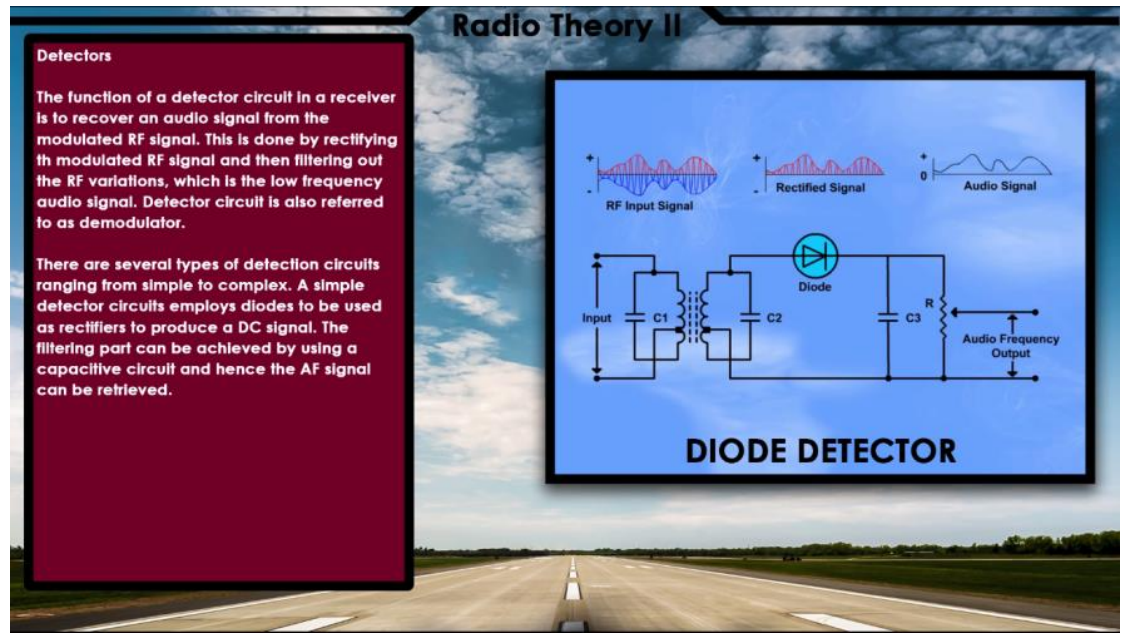

Gambar 5. Halaman Detector

g. Halaman Muting circuits

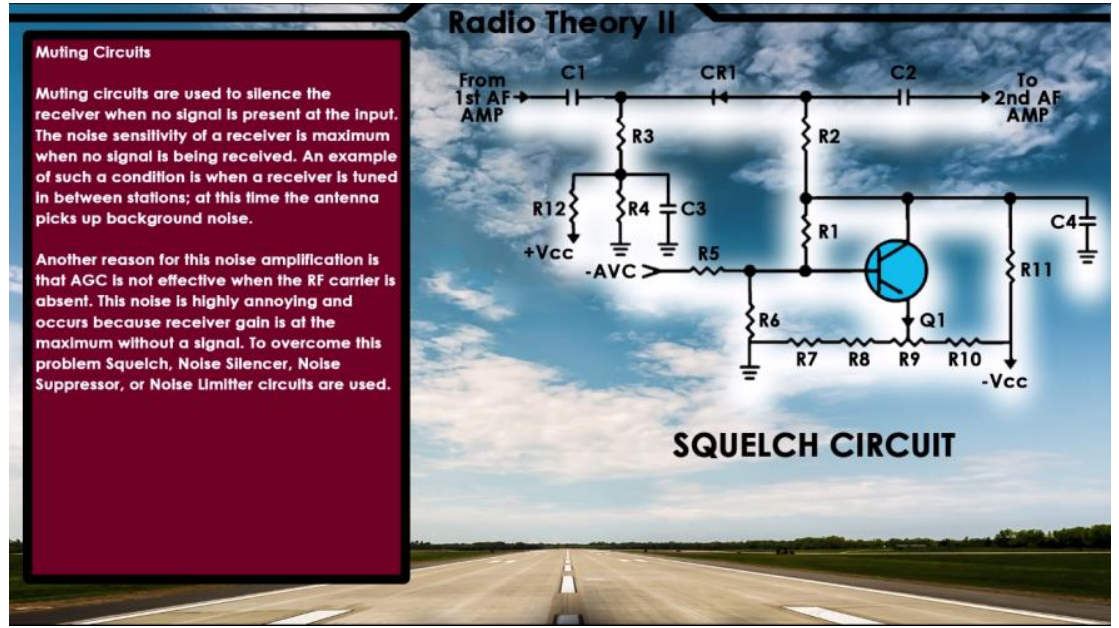

Gambar 6. Halaman Muting circuits

\subsection{Pengumpulan Bahan}

Material merupakan bahan yang penting dalam pembuatan Rancang Bangun Media Pembelajaran Avionic - Radio Theory II. Material dapat dibuat sendiri, membeli ataupun memanfaatkan material free yang terdapat di website-website tertentu. Dalam penyusunan Media Pembelajaran Avionic - Radio Theory II ini kami mendapatkan material asset animasi yang dibuat dengan aplikasi desktop dan sound dari text to spech balabolka dengan memanfaatkan asset yang dapat digunakan secara gratis.

\subsection{Pembuatan}

Rancang Bangun Media Pembelajaran Avionic - Radio Theory II ini dibuat dalam sebuah aplikasi photoshop dan adobe premiere untuk suara menggunakan text to spech dan Balabolka yang disusun sesuai timeline tertentu agar bisa menampilkan Multimedia Animasi.
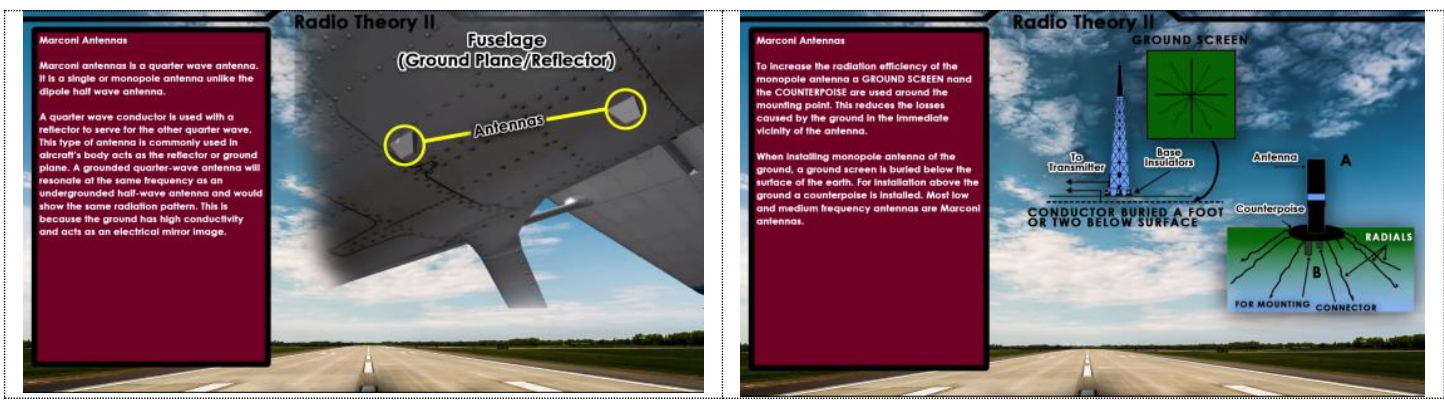

Gambar 7. Salah satu Tampilan slide halaman video 


\subsection{Pengujian}

Berikut penjelasan mengenai hasil testing Rancang Bangun Media Pembelajaran Avionic - Radio Theory II yang telah dibuat :

a. Media Pembelajaran Avionic - Radio Theory II berbentuk landscape yang sudah disesuaikan dengan resolusi Youtube sehingga tidak terlalu berat jika dijalankan nanti di android.

b. Setelah kita menekan play maka video akan menampilkan MEDIA Pembelajaran Avionic - Vh Radio Theory II F-HF Communication

Dari hasil pengujian yang telah dilakukan, dapat dilihat bahwa MEDIA PEMBELAJARAN AVIONIC - Radio Theory II yang telah dibuat dapat berjalan dengan baik.

\subsection{Distribusi}

Video AVIONIC - Radio Theory II sebagai bentuk digitalisasi Media Pembelajaran sudah selesai dibuat dan digunakan dilingkungan internal ATKP Medan dikemas dalam bentuk DVD.

\section{KESIMPULAN}

Dalam upaya meningkatkan mutu pembelajaran melalui Media Pembelajaran avionic- Radio Theory II secara digital yang dkemas dalam animasi multimedia. Dengan menggunakan metode Multimedia Development Life Cycle MDLC yaitu metode Konsep (Concept), Perancangan (Desain), Pengumpulan Bahan (Material Collecting), Pembuatan (Assembly), Pengujian (Testing), Distribusi (Distribution) berhasil di distribusikan dilingkungan ATKP Medan. Pengembangan media pembelajaran berbasis multimedia animasi ini dapat menjadi salah satu contoh implementasi digitalisasi Avionic agar cepat dipahami oleh para taruna. Selain daripada itu sebaiknya Avionic yang lain harus segera dilakukan digitalisasi

\section{REFERENCES}

[1] A. Z. Akhmad Busyaeri, Tamsik Udin, "PENGARUH PENGGUNAAN VIDEO PEMBELAJARAN TERHADAP PENINGKATAN HASIL BELAJAR MAPEL IPA DI MIN KROYA CIREBON,” Al Ibtida, vol. 1, no. 20, pp. 116-137, 2016.

[2] A. H. Dicky Candra Kurniawan, Dedi Kuswandi, "PENGEMBANGAN MEDIA VIDEO PEMBELAJARAN PADA MATA PELAJARAN IPA TENTANG SIFAT DAN PERUBAHAN WUJUD BENDA KELAS IV SDN MERJOSARI 5 MALANG," JINOTEP, vol. 4, no. 2, pp. 119-125, 2018

[3] D. Priyanto, "Pengembangan Multimedia Pembelajaran Berbasis Komputer," J. Pemikir. Altern. KEPENDIDIKAN, vol. 14, no. 1, pp. $1-13,2009$.

[4] M. E. D. Y. Endryansyah, "PENGARUH PENERAPAN MEDIA PEMBELAJARAN PhET ( Physics Education Technology SIMULATION TERHADAP HASIL BELAJAR SISWA KELAS $X$ TITL PADA STANDAR KOMPETENSI MENGAPLIKASIKAN RANGKAIAN LISTRIK DI SMKN 7 SURABAYA,” J. Pendidik. Tek. Elektro, vol. 4, no. 2, pp. 407-414, 2015.

[5] A. wedi Lukman Arief Novianto, I Nyoman Sudana Degeng, "Pengembangan Multimedia Interaktif Mata Pelajaran IPA Pokok Bahasan Sistem Peredaran Darah Manusia Untuk Kelas VIII SMP Wahid Hasyim Malang,” JKTP, vol. 1, no. 3, pp. 257-263, 2018.

[6] R. Idris, Iswandi; Hasibuan, Helviana; Efriza, Doni; Sari, Aditya, "Ibm Peningkatan Produktivitas Kelompok USAha Roti 'NenotNenot’ Kelurahan Suka Ramai Medan,” J. Teknovasi J. Tek. dan Inov., vol. 4, no. 1, pp. 51-58, 2017.

[7] I. Idris and Y. Delvika, "ANALISIS PERANCANGAN SISTEM INFORMASI TERINTEGRASI DI LINGKUNGAN PERGURUAN TINGGI SWASTA DI MEDAN,” J. Teknovasi, vol. 1, no. 2, pp. 15-26, 2014.

[8] Wikipedia, “Avionics," Wikipedia, 2018. [Online]. Available: https://en.wikipedia.org/wiki/Avionics. [Accessed: 17-Aug-2019]

[9] I. M. Faizal, N. Nurhasanah, and E. Rahmawati, "Digitalisasi Permainan Tradisional Galah Melalui Media Game," vol. 1, no. 1, pp. $17-21,2019$. 